\title{
The first fossil opilioacariform mite (Acari: Opilioacariformes) and the first Baltic amber camel spider (Solifugae)
}

\author{
Jason A. Dunlop, Jörg Wunderlich and George O. Poinar Jr
}

\begin{abstract}
The first fossil opilioacariform mite (Acari: Opilioacariformes), Paracarus pristinus sp. n., is described from Baltic amber (Tertiary: Eocene). This well-preserved inclusion has six eyes and, thus, can be excluded from the derived, four-eyed genera. Based on characters such as the extremely long leg 4, it is assigned to the extant central Asian genus Paracarus Chamberlin \& Mulaik, 1942. As with many Baltic amber inclusions, we lack an exact provenance for the type specimen, but the Baltic region is further north than the present day range of Recent opilioacariform species and suggests that the range of this group was once more extensive within Eurasia. The first solifuge (Solifugae) from Baltic amber is described as Palaeoblossia groehni gen. et sp. n. Based on its size and general appearance, it can be assigned to Daesiidae, and again represents an arachnid group which previously had a much wider geographical range. If adult, it may represent the smallest solifuge known.
\end{abstract}

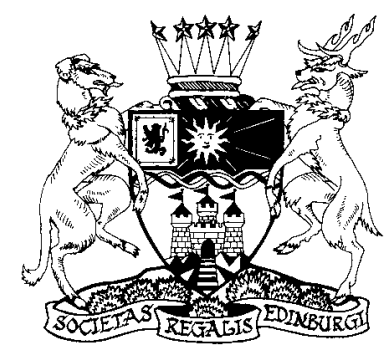

KEY WORDS: Arachnida, Arthropoda, biogeography. Eocene

Fossil mites (Arachnida: Acari) are generally rather rare, although they are quite frequent and diverse in Baltic amber. Useful summaries can be found in Bernini (1986), Selden (1993), Lourdes (1999) and Klompen \& Grimaldi (2001). Leaving aside debates about the monophyly of mites, some authors (Lehtinen 1980; Harvey 1996, 2002; Walter \& Proctor 1999; Lourdes 1999) treat the Acari as a putative clade comprising three distinct higher taxa, nominally assigned the rank of order. These are: Acariformes (the 'mites'), Parasitiformes (predatory mites and ticks) and Opilioacariformes. By contrast, many acarologists (e.g. Alberti 1980; Bernini 1986; Vázquez \& Klompen 2002) recognise only two clades, again nominally of ordinal rank, and see no major distinction between opilioacariforms and parasitiforms, which they group together as a monophyletic taxon. This reflects a fundamental division into actinotrichid (= acariform) and anactinotrichid (= parasitiform + opilioacariform) mites. Opilioacariforms, which are sometimes referred to as Notostigmata (Evans 1992, p. 382), are extremely rare (23 extant species in eight genera; c.f. Vázquez \& Klompen 2002), and are widely perceived as primitive mites on account of their fairly large size, their superficial resemblance to cyphophthalmid harvestmen (Opiliones) and their retention of ostensibly plesiomorphic characters (e.g. Harvey 1996), such as four or six eyes, two pedipalpal claws and a clearly segmented body.

The oldest putative mite is a recently described oribatid (or cryptostigmatid) from the Early Ordovician of Sweden (Bernini et al. 2002), which, if not a contaminant, is also the oldest record of an arachnid. The Early Devonian Rhynie cherts (Hirst 1923) yield a handful of further acariform taxa assignable to the actinedid (or prostigmatid) mites (see also Bernini 1986, fig. 28). These are closely followed by further oribatids from the Middle Devonian of Gilboa (Norton et al. 1988). By contrast, the oldest parasitiform mite, an argasid bird tick, comes from Cretaceous New Jersey amber (Klompen \& Grimaldi 2001), and the comparatively late and meagre record of parasitiform mites includes a few ixodid ticks and predatory gamasid mites mostly from Baltic amber (e.g. Witaliński 2000). Indeed, Lourdes (1999) speculated that mite evolution may have involved two phases of adaptive radiation; first in the mid-Palaeozoic, and subsequently, in the late Mesozoic. Until now, opilioacariform mites were absent from the fossil record. Sensu Harvey (2002), this rendered them the only arachnid order with no fossil representatives. The widely accepted [Acariformes (Parasitiformes + Opilioacariformes)] cladogram predicts that the opilioacariform lineage should have appeared by at least the Cretaceous, the minimum time for their divergence from the parasitiform mites. Realistically, all the major mite groups are probably extremely old, but their small size and unmineralised cuticle seriously reduces their chance of being preserved as fossils, except in cases of extraordinary preservation such as in amber. In fact, Baltic amber has proven to be the most productive source of fossil mites (e.g. see citations in Keilbach 1982; Sayre et al. 1992; Coineau \& Magowski 1994; Witaliński 2000). Previously recorded taxa include ixodid ticks, trombiforms, gamasids, caeculids and a diverse assemblage of oribatid (soil) mites; (e.g. see Selden 1993 for details).

Solifuges (i.e. camel spiders, sun spiders and wind scorpions) are even rarer as fossils than mites. An enigmatic specimen with some solifuge-like features has recently been discovered from the Lower Carboniferous of Poland (Dunlop \& Rößler 2003), while a poorly preserved, but identifiable, solifuge has been described from the Upper Carboniferous of Mazon Creek, USA; see Shear in Selden \& Shear (1996) for a redescription. These very old fossils are interesting in that they come from what are generally interpreted as humid coal swamp environments as opposed to the dry habitats characteristic of most modern forms. Mesozoic solifuges have been described from the Lower Cretaceous of the Crato Formation, Brazil (Selden \& Shear 1996). This beautifully preserved material could be assigned to the extant southern African family Ceromidae, and suggests that this group was also distributed in what is now Brazil before the rifting of Pangea. Further material from Crato awaits description (Dunlop \& Martill in press). The only Tertiary record is a fossil from Dominican amber (Poinar \& Santiago-Blay 1989) that was assigned to a new genus of the American family Ammotrechidae, a group 
that still occurs today on Caribbean islands and elsewhere in mainland America (Punzo 1998).

In the present paper, the authors describe the first fossil opilioacariform mite, a beautifully preserved inclusion from Baltic amber (Figs. 1, 2). This important find can be assigned to the extant central Asian genus Paracarus Chamberlin \& Mulaik, 1942, and represents the most northerly record of the entire clade. The first solifuge from Baltic amber (Figs 3-6) was initially figured in a general book on Baltic amber arthropods (Janzen 2002), and is here formally described and named. It is an exquisitely preserved small male referable to the extant and widespread family Daesiidae, a number of which still live in southern Europe. Again, it is the most northerly record of this group.

\section{Material and methods}

The opilioacariform specimen is held in the collection of JW (Laboratory of Arachnology in Straubenhardt: F1011/BB/AR/ CJW), and will eventually be deposited in the Senckenberg Museum Frankfurt/Main, Germany (SMF). The solifuge is part of the Carsten Gröhn collection held in the GeologicalPalaeontological Museum of the University of Hamburg, Germany (GPIUH) and has the Hamburg repository number 4312. It also bears the original Gröhn collection number of 3913. Amber is very difficult to date accurately, but these Baltic inclusions are generally assigned to an Eocene age (c. 38-54 Ma).

The specimens were drawn using a Leica MZ12 stereomicroscope with a camera lucida attachment. Van der Hammen (1976) developed an extensive morphological terminology specifically for opilioacariform mites. The present authors draw on this, but preferentially use terms which better allow comparisons with other arachnid groups in general; for example, they use patella rather than genu for the limb article following the femur. The fossil mite was compared to extant specimens of an unidentified opilioacariform mite, possibly Opilioacarus (Neocarus) sp. from Mexico - nomenclature after Vázquez \& Klompen (2002) - and to the literature. Solifuge terminology generally follows Roewer (1932-4), Wharton (1981) and Punzo (1998), except that limb terminology is derived from Shultz (1989). The fossil was compared to extant solifuge material in the zoological collections of the Berlin museum. All measurements are in millimetres.

\subsection{Preservation}

The opilioacariform fossil is an almost complete animal enclosed in a clear piece of golden amber that may have been slightly heated. It can be examined from both the dorsal and ventral sides. The amber contains some dark organic/inorganic bodies near the anterior limbs, but they do not seriously obscure the specimen. Right legs 1 and 2, as well as left legs 3 and 4 , have been lost. Unequivocal haemolymph droplets at the leg stumps are lacking, as might be expected if leg loss was part of the entrapment process. The first left leg is slightly disarticulated and lies in front of the body. Its ventral side is covered by a thin, white emulsion. Tiny remains of two stellate hairs are preserved at the surface of the piece of amber.

The solifuge is a complete and exquisitely preserved animal, c. $5 \mathrm{~mm}$ long. It is enclosed in a piece of yellow amber which was originally cleared in a benzylester. This resulted in a darkening of the specimen. The ventral side is covered with a thick, white emulsion (often encountered in Baltic amber fossils) and is not figured here. Anterior parts of the chelicerae and the opisthosoma are partly obscured by imperfections in the amber. Some stellate hairs are present in the amber.

\section{The opilioacariform mite}

The specimen (Figs 1,2) is about $1.8 \mathrm{~mm}$ long, with a broadly oval body. Although extant species are often described as being quite brightly coloured, any original colouration has been lost and the fossil is pale brown, the legs slightly darker than the body. Like extant forms (e.g. see SEM figures in Kaiser \& Alberti 1991), the dorsal surface of the body is covered with a dense cuticular ornament of fine tubercles. This ornamentation also continues onto the legs (see section 2.3).

\subsection{Gnathosoma}

The gnathosoma of mites is an anterior body tagma that comprises the mouth lips, chelicerae and the pedipalps, and articulates against the rest of the body (the idiosoma). The basal parts of the gnathosoma in this fossil are difficult to resolve, being obscured by white emulsion. This is unfortunate since the setation of the gnathosoma yields a number of important characters in the taxonomy of extant species. A small dark element with finger-like distal projections is one of the paired rutella, characteristic opilioacariform structures thought to be highly modified setae which insert onto the gnathosoma below the chelicerae. The presence or absence of a further co-occurring element, With's organ, cannot be resolved. According to van der Hammen (1968), this second type of modified seta is not present in the genus Paracarus to which the present fossil can potentially be referred.

Only one of the paired chelicerae can be seen. It is quite elongate in comparison to other extant taxa (Redikorzev 1937; van der Hammen 1989) and comprises three articles, the distal two forming a chelate claw. The middle article expresses almost a pseudoarticulation, with a distinct narrowing of the distal half compared to the proximal half. The free finger of the claw is partly obscured by a plane of fracture in the matrix. Setae are not clearly preserved on the chelicera. The pedipalps are short, stubby, pediform appendages. The total number of articles is unclear (living taxa have six plus the claws), but the distal tarsus is quite setose. Two claws would be expected, but these cannot be resolved in this material.

\subsection{Idiosoma}

The remainder of the body forms the idiosoma. In opilioacariform mites, there are clearly two distinct parts to the idiosoma, but it is unclear whether these anterior and posterior sections correspond segmentally to the prosoma and opisthosoma of other arachnids, or to the proterosoma and hysterosoma division - effectively dividing the body between leg pairs 2 and 3 - seen in many mites (e.g. Bernini 1986, fig. 16). Since there are alternative ways of interpreting the segmentation of the opilioacariform body, use of terms like carapace or prosoma may be premature and misleading. Van der Hammen (1989) used the term prodorsum for the anterior part, but the present authors follow Klompen (2000) and refer simply to an anterior and posterior area.

The anterior area of the idiosoma forms a unitary dorsal shield. This is sub-triangular in shape and bears six eyes, arranged in two groups of three towards the lateral margins of the carapace. Each eye group comprises two larger, oval eye lenses, whose long axes point slightly towards each other, and a smaller, circular eye lens in between them, which is positioned slightly more towards the median side. Medial to the eyes, a broad central region is defined by a pair of curving sulci, probably the oculorostral grooves of van der Hammen (1968). Towards the back of this shield, there is a procurved groove, or transverse furrow sensu van der Hammen, and the posterior margin of the shield itself is also more-or-less 
procurved. As in extant forms, the central region bears a scattering of papilliform setae forming a poorly defined median band.

Dorsally, the posterior area is formed from a number of tergites. There seem to be at least nine in total, but the central region is slightly broken up and overlain by leg 4 . Van der Hammen (1968) noted that, even within a species, the degree of externally visible segmentation can vary depending on conditions within the body and the way that (living) material has been preserved. In the present fossil, the two or three anteriormost tergites are very short, and, towards their lateral margins, they form grooves representing muscle attachment sites called laterodorsal sigilla (van der Hammen 1989). These short tergites are followed by a series of much longer tergites. Interestingly, the present authors would expect a series of paired, round spiracles on the dorsal surface from about the third segment onwards, but these cannot be resolved in this specimen. Very early instars lack these spiracles, but other features (see section 2.4) suggest that we are dealing with a more advanced ontogenetic stage. Posteriorly, there is no clear anal tubercle, but as noted by van der Hammen, this protruding, terminal structure can be retracted in life.

Ventrally, a pair of divergent pointed projections called sternapophyses would be expected between the anteriormost leg coxae, but these are not visible here, and in general, a broad, pale patch occupying the intercoxal region appears to be an overlying artefact obscuring the morphology. Behind this, there is a slight development on the right side adjacent to coxa 4, which is conceivably a genital verruca. Behind the coxae, there is a set of well-preserved segmental divisions. These become successively wider with grooves or ventral sigilla (again muscle apodemes) at their lateral margins. However, they do not continue across the entire ventral surface and cannot really be called sternites. These divisions define six fairly short segments. The posterior part of the body does not express any segmentation, again consistent with living species.

\subsection{Legs}

The legs are conventionally numbered from (1) anterior to (4) posterior. The legs are elongate, and like the dorsal surface of the body, they bear an ornament of fine tubercles. This becomes harder to see towards the distal ends. Legs 1 and 2 are missing from the right side, and legs 3 and 4 from the left side. Coineau \& Legendre (1975) noted the ease with which living taxa tend to lose appendages and described an unusual form of regeneration which involves adults moulting. All mites characteristically have hexapodal early instars. The ventral view (Figs 1b, 2b) clearly shows two legs plus two coxae in the fossil from which legs are missing on the right side, thus the animal was at a stage which had the full complement of four pairs of legs (see also section 2.4). These coxae clearly sit in a lateral concavity on the underside of the body. As in extant species, the legs are ornamented by a mixture of two types of setae: tapering 'ordinary' setae, which usually lie at an angle relative to the limb, and the thicker, somewhat club-shaped papilliform setae which typically stand almost perpendicular to the cuticle. Both types of setae tend to form discrete rows along the leg articles. Van der Hammen $(1976,1989)$ offered further refinements of setal terminology, but with the specimen enclosed in amber, it is hard to resolve the structure of individual setae at a higher magnification.

The trochanter of leg 1 is elongate, when compared to arachnids in general, and quite robust. The femur is also long and widens distally. Proximally, there appears to be an additional short article. A similar structure is clearly illustrated by van der Hammen (1968, fig. 4) in Paracarus hexophthalmus (Redikorzev, 1937), but its precise identity (a pseudoarticle of the femur?) is unclear and this element can also be seen in other taxa. The patella is very long and is followed by a slender tibia. The terminal end of leg 1 , the basitarsus and telotarsus, has a particularly dense concentration of ordinary setae, and the whole leg (the longest of the four) may have been used in an antenna-like fashion to probe ahead of the animal (cf. Grandjean 1936). Legs 2 and 3 are shorter and have more papilliform setae than leg 1 . In both these legs and leg 4 , the basitarsus is a relatively elongate article, longer than the adjacent tibia. Leg 4 is the most robust limb. There are unequivocally two trochanters (see section 2.4) and the papilliform setae along the length of the whole leg are particularly tall and well-developed. Generally, the terminal claws of the legs are poorly preserved, but as in extant taxa, leg 4 clearly ends in a pair of short, curving claws either side of a fleshy adhesive pad called the pulvillus.

\subsection{Which instar?}

The ontogenetic sequence for opilioacariform mites is: prelarva, larva, protonymph, deutonymph, tritonymph and adult (Coineau \& van der Hammen 1979). The prelarva and larva lack the full complement of legs (Klompen 2000), and therefore, the present fossil must be a protonymph or later. In at least one extant genus investigated in detail, Phalangiacarus, the appearance of two trochanters in legs 3 and 4 characterises the tritonymph, and this second trochanter is present in at least leg 4 of the present fossil. Less obvious are the setose genital verrucae which would be expected between the fourth coxae on the ventral surface. There is a hint of some development here on the left side (Fig. 2b), and this is most reminiscent of published illustrations of a female Phalangiacarus tritonymph (Coineau \& van der Hammen 1979, fig. 2A); male tritonymphs in this genus already express a more complex morphology here at this stage. The present authors suspect that the fossil may be a tritonymph, but detailed comparative data from other extant genera are lacking.

\section{The solifuge}

\subsection{Prosoma}

The prosomal dorsal shield of solifuges is essentially formed from three separate plates: the pro-, meso- and metapeltidium. In the present fossil, the propeltidum is roughly hemispherical and bears the single pair of median eyes on a raised ocular tubercle at the anterior margin. The propeltidium is clearly divided by a median sulcus (Figs 3,4), which extends to the back of the sclerite, while at the antero-lateral margins, the so-called exterior lobes are clearly visible. These are partially separated off from the rest of the propeltidium by short sulci, however, they are clearly attached to the rest of the propeltidium and are not separate plates, a noteworthy taxonomic character. The propeltidium bears a few setae and has a series of dark impressions immediately beneath the cuticle which have a vaguely symmetrical arrangement and are probably evidence of the original underlying musculature. Similar internal muscle scars can be seen elsewhere on the appendages.

The region immediately behind the propeltidium is complex and includes a narrow band of cuticle comprising the so-called arcus anterior and plagula mediana (see also Roewer 1932-4). This band can be clearly seen in the fossil, but another set of expected sclerites, the arcus posterior, is difficult to see. In terms of tagmosis, these sclerites are usually included with the propeltidium, the whole tagma being associated with the chelicerae, pedipalps and first two pairs of walking legs. The tergites of the succeeding prosomal segments, the meso- and 

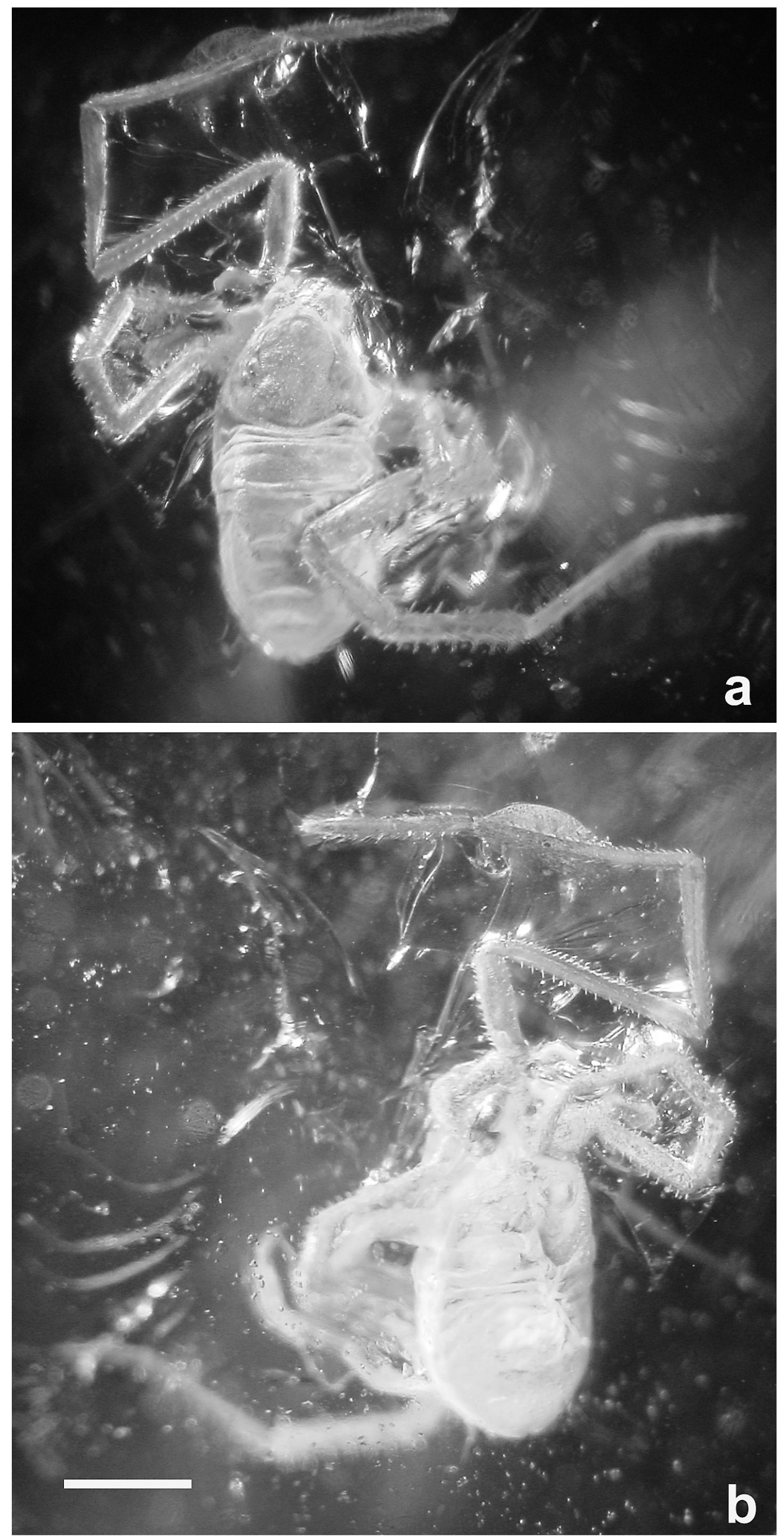

Figure 1 Paracarus pristus sp. n., the first fossil opilioacariform mite, from Baltic Amber (Tertiary: Eocene) (F1011/BB/AR/CJW): (a) dorsal surface; (b) ventral surface. Scale bar $=0.5 \mathrm{~mm}$. 

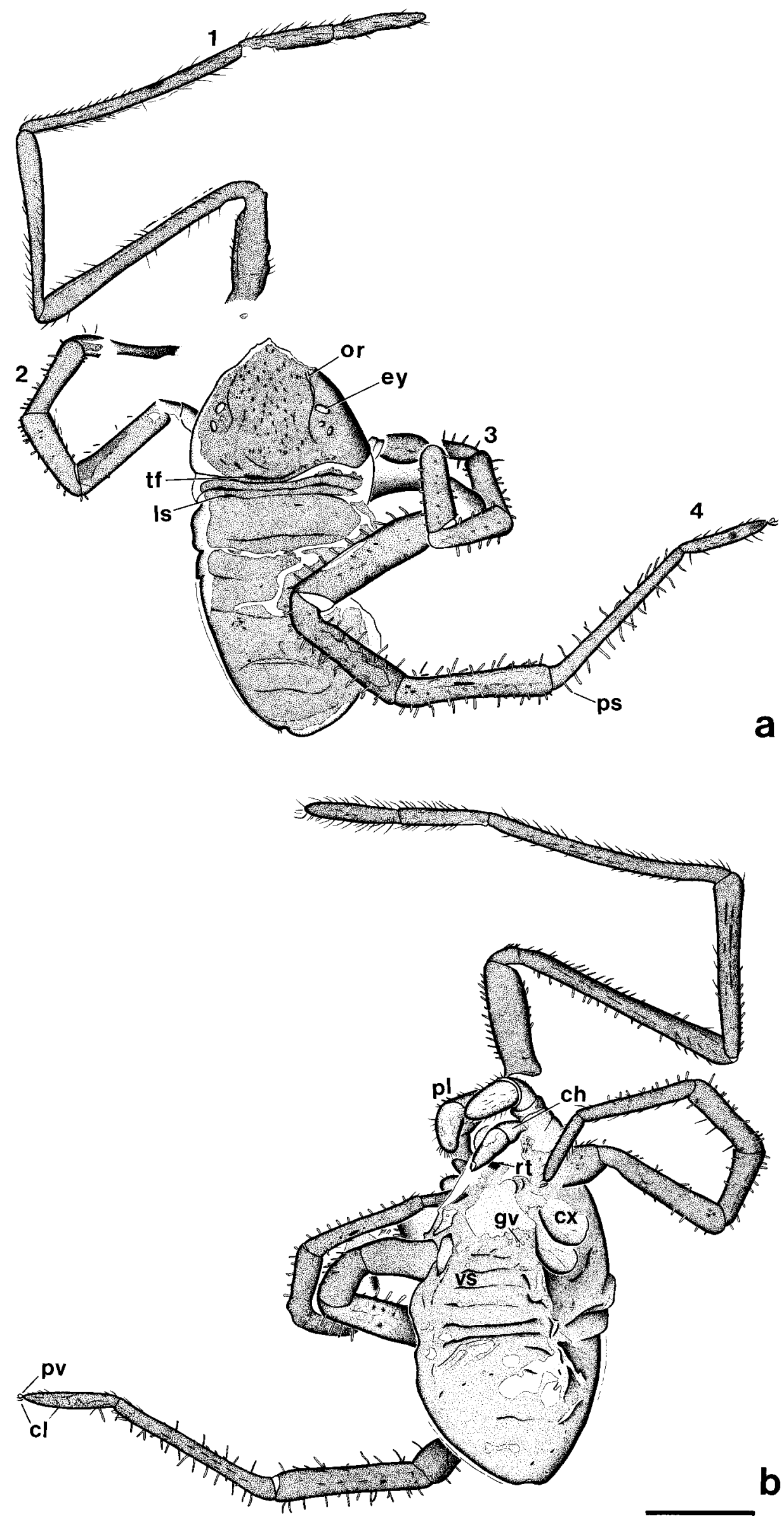

Figure 2 Camera lucida drawings of the specimen shown in Fig. 1: (a) dorsal surface; (b) ventral surface. Note the similar lengths of legs 1 and 4 . Abbreviations: (ch) chelicera; (cl) paired claws; (cx) coxa; (ey) eyes; (gv) genital verucca-like structure; (ls) laterodorsal sigilla; (or) oculorostral groove; (pl) pedipalp; (ps) papilliform seta; (pv) pulvillus; (rt) rutellum; (tf) transverse furrow; and (vs) ventral sigilla. Legs numbered $1-4$. Scale bar $=0.5 \mathrm{~mm}$. 


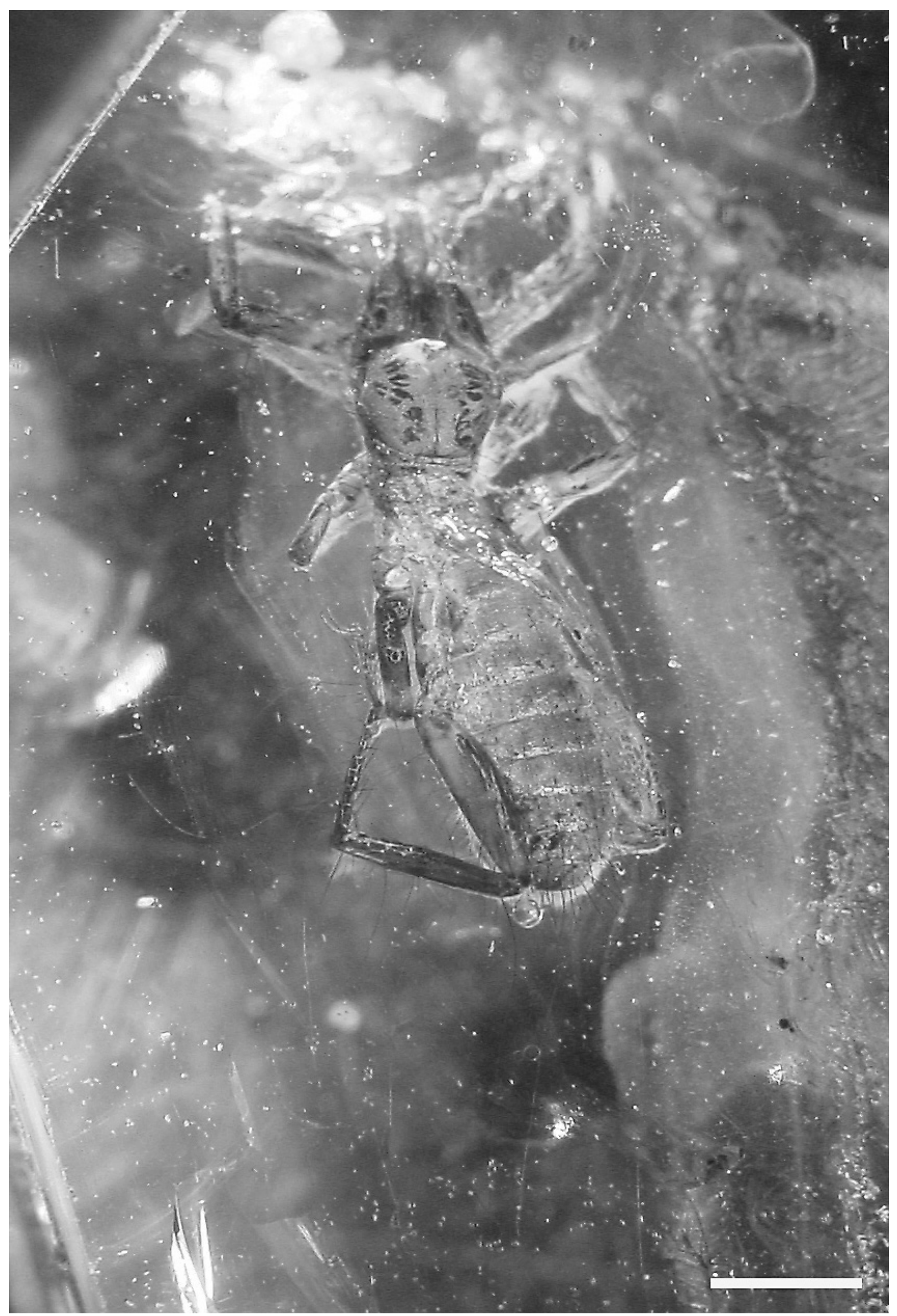

Figure 3 Palaeoblossia groehni gen. et sp. n., the first solifuge from Baltic amber (GPIUH 4312). Scale bar $=1 \mathrm{~mm}$. 


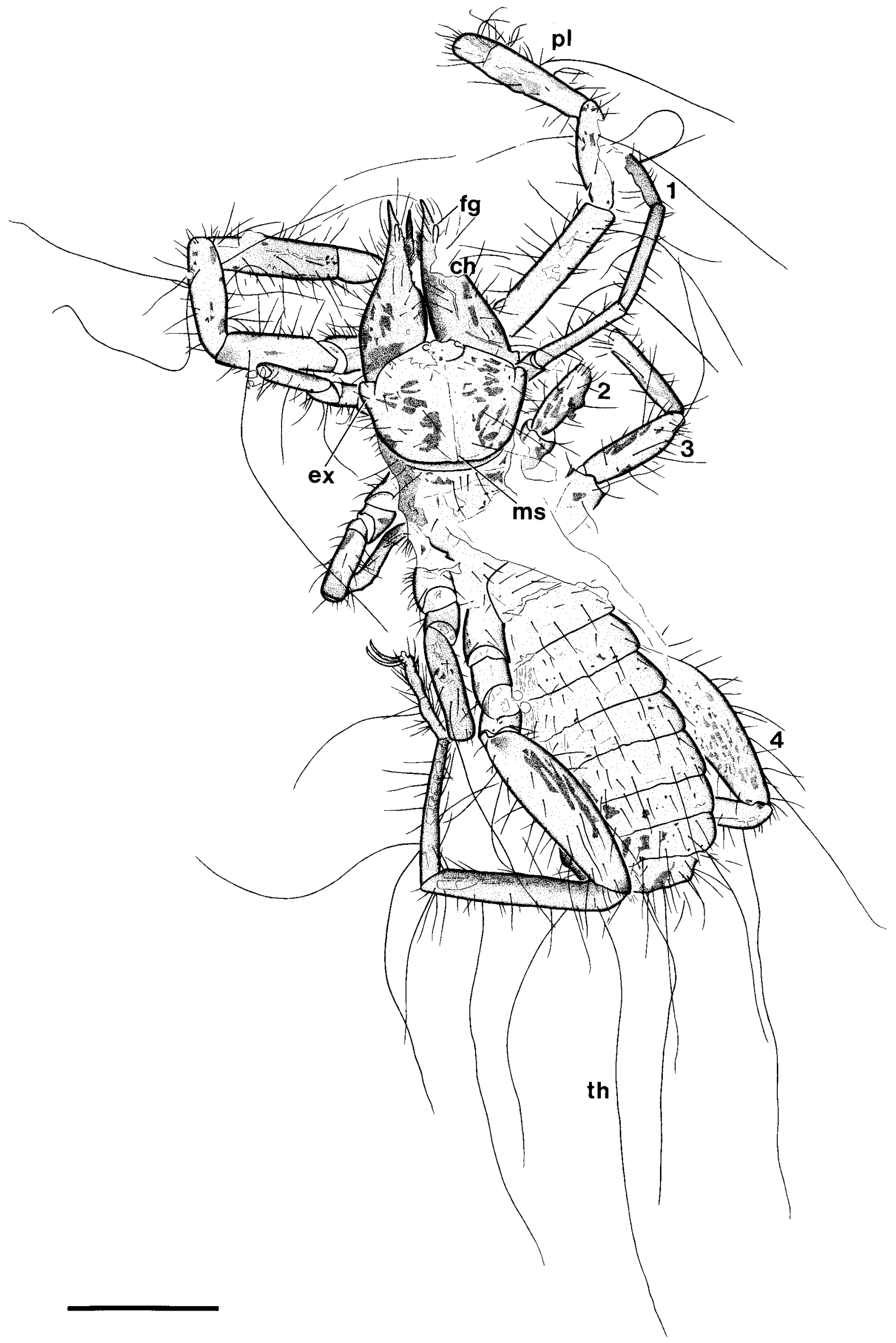

Figure 4 Camera lucida drawing of the specimen shown in Fig. 3. Dark patches indicate underlying musculature. Abbreviations: (ch) chelicera; (ex) exterior lobe of propeltidium; (fg) flagellum; (ms) median sulcus of propeltidium; (pl) pedipalp; and (th) elongate tactile hair. Legs numbered $1-4$. Scale bar $=1 \mathrm{~mm}$. 
metapeltidium, are poorly defined in the fossil and a fault in the matrix partly obscures this region. A number of setae originate here nevertheless. There is a slight bending of the body here to the right which reflects the general mobility of the entire solifuge prosomal region.

\subsection{Opisthosoma}

The opisthosoma has an elongate oval shape, and from a total of eleven segments, nine tergites can be discerned in the fossil. The present authors suspect that the anteriormost tergite (1) is poorly preserved since it is often hard to see, even in extant material, while the short posteriormost segment (11) which bears the anus has folded underneath the preceding tergite. The tergites all have straight posterior margins and are sparsely ornamented with setae. The longer opisthosomal hairs form a distinct pattern with rows of at least three regularly placed hairs. The setation becomes more dense distally and the posteriormost tergites bear a denser coat of medium length hairs plus a few much longer (c. $2 \mathrm{~mm}$ ) tactile hairs. The more anterior tergites express a slight folding or shrinkage of the cuticle on the left side near the base of leg 4 .

\subsection{Chelicerae}

The chelicerae are characteristically massive and robust, making up about half the length of the whole prosomal region. Again, muscle scars are present, while part of the right chelicera is obscured. The chelicerae are dentate towards the distal end. This dentition is often of taxonomic significance in extant solifuges, but from the dorsal view, precise details of this dentition in the fossil are obscure. The chelicerae are setose, while on their inner, mesal surface, there is a slightly thicker brush of more plumose hairs towards the distal end in the region of dentition. These can also be seen in ventral view. The mesal surface of the chelicerae bears file-like stridulatory structures, comprising a series of longitudinal ridges which can be rubbed against each other (Fig. 6a).

Close to the anterior end of each fixed finger, there is a small dorsal projection - only clearly visible under higher magnification (Fig. 6a) - which the present authors suggest is probably the flagellum. This sexually dimorphic character in all families bar one is absent in females, and while its precise function remains obscure (see Punzo 1998 for an overview), it would identify the inclusion as a male. The flagellum is present in pre-adult and adult instars, and implies that the fossil was either sexually mature or one moult from maturity. The flagellum can be quite complex and is often an important taxonomic character in extant solifuges. In this fossil, it appears simple, awl-shaped and widens towards the distal end. The mobility or otherwise of the flagellum is an important familial character, but this remains equivocal in the fossil, which seems to show a simple insertion point on the main body of the chelicera. Interestingly, the fossil flagellum appears to be directed forwards. The flagella in most solifuges tend to be illustrated pointing backwards (e.g. see Roewer 1932-4), although the flagella are directed forwards in some of the daesiids figured by Delle Cave \& Simonetta (1971), for example. An alternative interpretation is that this cheliceral structure is a principal seta sensu Wharton (1981), which he noted as a short, stout, anteriorly directed seta on the dorsal cheliceral finger of daesiid solifuges, which inserts near the base of the flagellum. In this hypothesis, the actual flagellum in the fossil would be missing.

\subsection{Pedipalps}

As in all extant solifuges, the pedipalps are robust and pediform. Textbook accounts following Roewer (1932-4) generally name the pedipalpal articles as the femur, tibia, metatarsus and tarsus. This scheme was based on an erroneous assumption that solifuges lack a patella in all their limbs. This problem has been discussed in detail for the walking legs by Shultz (1989), and like Selden \& Shear (1996), the present authors recognise the articles here as the femur, patella, tibia and tarsus, the normal pattern for arachnids. The femur is the longest article in the fossil, followed by the tibia and patella, while the tarsus forms a short, bluntly rounded tip to the appendage. The pedipalps are highly setose. The (left) femur includes a tactile hair over $2 \mathrm{~mm}$ long, while the patella and tibia both include a single long hair about $1.5 \mathrm{~mm}$ long.

\subsection{Legs}

As noted above, Shultz (1989) rejected the hypothesis that solifuges lack a patella, and redefined the leg articles based on their musculature as trochanter, basifemur, telofemur, patella, tibia, basitarsus and tarsus. Thus, solifuges differ from most other arachnids in having a divided femur comprising two rather short articles (the basi- and telofemur), while the patella is considerably longer and looks superficially like the femur in groups such as spiders. Leg 1 in the fossil is relatively gracile and it often has more of a tactile function than a walking one in extant solifuges. Reflecting this, the leg 1 tarsus lacks distal claws in some solifuges, but this character cannot be assessed in the fossil. Legs 2 and 3 are more robust in the inclusion, but are, to some extent, tucked under the body so that only the proximal articles can be seen clearly. Leg 4 is the largest and most robust. Some of the longest tactile hairs (over $2.5 \mathrm{~mm}$ ) stem from leg 4. A small phoretic nematode (Rhabditida sp.) is attached to the ventral surface of the right third femur (Fig. 6b).

Of particular significance is the distal end of leg 4, which is nicely preserved in lateral view. The large paired claws, or ungules, clearly show the characteristic solifuge division into a long main body and tiny apical claws (Fig. 5). Between these claws is another typical solifuge feature, a fleshy pad or pulvillus which may have an adhesive function. Tarsal segmentation and spination is usually considered to be of considerable taxonomic significance, although it must be noted that, even among extant animals there are cases of serious discrepancies in the descriptions of these genus-level diagnostic characters (e.g. see Delle Cave \& Simonetta 1971), with Roewer's work typically emerging as the primary source of errors and confusion. In the fossil, tarsus 4 unequivocally consists of two segments separated by a weak articulation in which the distal segment is slightly longer than the proximal one. True spines, which are shorter and thicker than the normal tactile hairs, appear to be absent on the tarsus, at least none can be clearly distinguished in lateral view (Fig. 5).

\section{Systematic Palaeontology}

\section{Opilioacariformes Zachvatkin, 1952}

Remarks. Both Opilioacarida and Notostigmata, the latter name referring to the dorsal spiracles, occur frequently in the literature. Opilioacarida appears to have first been used explicitly as an ordinal name by Zachvatkin (1952, p. 6), although he assigned authorship (p. 44) to With. In fact, With (1902) only named the genus and (With 1904) named Notostigmata as a suborder. Johnston (1968) is sometimes cited as the author of the emended version Opilioacariformes, a spelling which also occurs - apparently as a lapsus - on page 41 in the posthumous section of the Zachvatkin (1952) paper prepared by A. B. Lange. Here, the present authors follow Harvey (2002) in using 


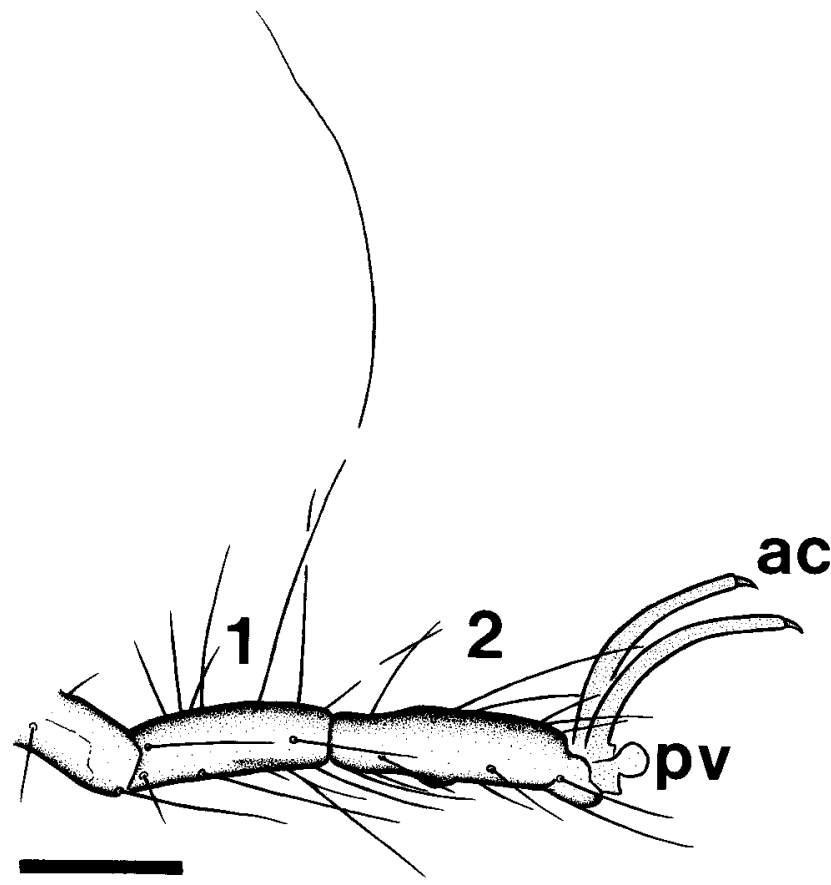

Figure 5 Detail of the leg 4 tarsus in P. groehni. Note the division of the article into two sub-equal sections (1-2) and the lack of clear ventral spination. Abbreviations: (ac) tiny apical claws; and (pv) pulvillus. Scale bar $=0 \cdot 2 \mathrm{~mm}$.

Opilioacariformes as the correct name, and assign authorship to Zachvatkin, who recognised its suprafamilial status. We leave the rank open since, as noted above, some authors ascribe ordinal status to this name, while others regard it as a subtaxon of Parasitiformes.

\section{Family Opilioacaridae Vitzthum, 1931}

Remarks. Van der Hammen (1968) commented on the fact that the opilioacarids are a fairly homogeneous group. Although there have been previous attempts to establish additional families (Chamberlin \& Mulaik 1942), all eight Recent genera are currently placed within a single family, Opilioacaridae (e.g. van der Hammen 1989; Harvey 2002; Vázquez \& Klompen 2002), whose authorship can be ascribed to Vitzthum (1931, p. 142).

\section{Genus Paracarus Chamberlin \& Mulaik, 1942}

Type species. Opilioacarus hexophthalmus Redikorzev, 1937. From central Asia (Kazakhstan-Kyrgyzstan), Recent.

Emended diagnosis. Opilioacarids with a very long leg 4, which approaches (this fossil), or exceeds ( $P$. hexophthalmus), the length of leg 1. Emended from van der Hammen (1968).

Remarks. Of the eight currently recognised genera, only two have three pairs of eyes like the present fossil: Paracarus which was redescribed and rediagnosed by van der Hammen (1968) - and the Thai genus Siamacarus Leclerc, 1989. The polarity of this eye character requires discussion. The character transformations shown by van der Hammen (1970, fig. 2), imply that the six-eyed condition is plesiomorphic, but oddly, this was not reflected in his accompanying dendrogram of relationships between genera. By contrast, the cladogram of Harvey (1996) resolved the two, six-eyed genera as sister taxa to all other opilioacariform mites, which can be united on the autapomorphy of reduction of one of the eye pairs. Therefore, six eyes are symplesiomorphic and a poor diagnostic character,
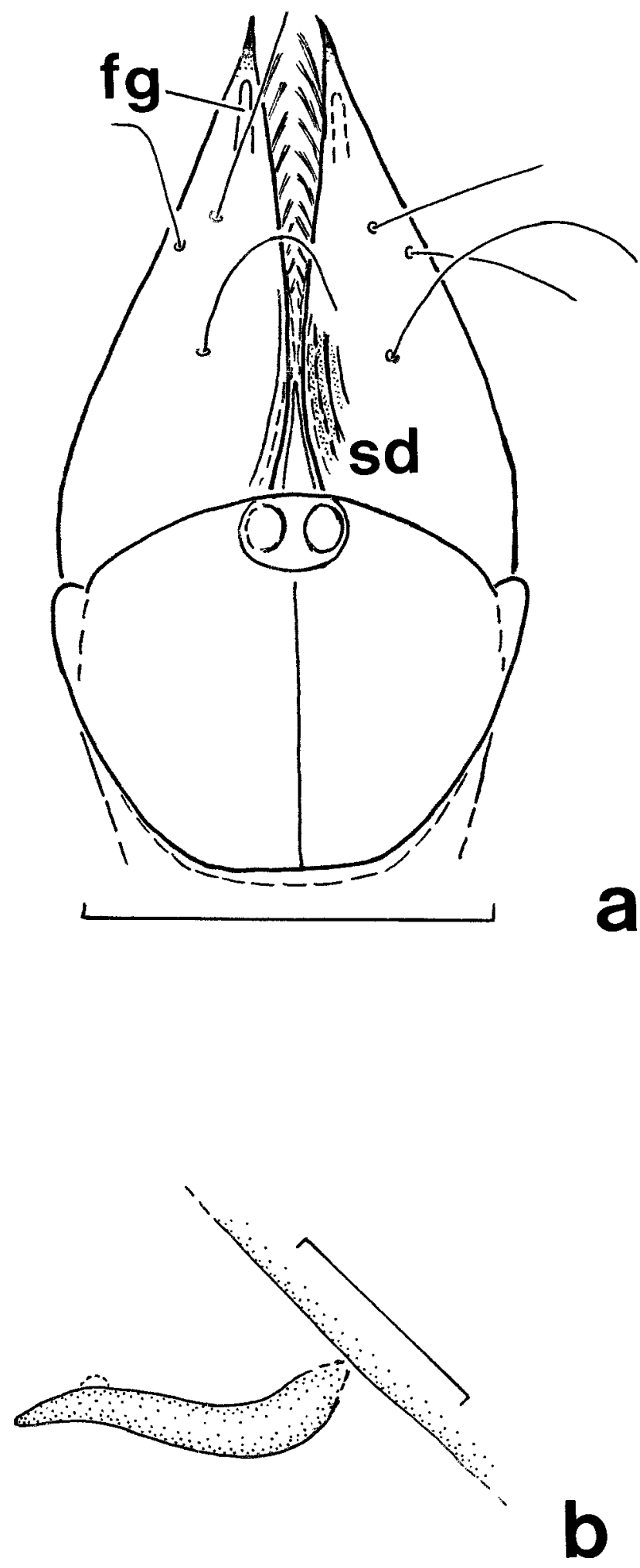

Figure 6 Palaeoblossia groehni. (a) Detail of the prosomal region showing the flagellum (fg) and stridulatory structures (sd) on the chelicerae. Scale bar $=0.5 \mathrm{~mm}$; (b) A phoretic nematode attached to the right third femur. Scale bar $=0 \cdot 1 \mathrm{~mm}$. Drawings by JW.

but the present fossil can be excluded from all the more derived genera with only four eyes.

Leclerc's Siamacarus is a cave genus with two species, diagnosed on the presence of a serrula - or series of tooth-like projections - on the movable finger of the chelicera and two ventral trichobothria on the femora of the walking legs. Neither of these characters appear to be present in this new fossil, and thus, the present authors tentatively exclude it from 
this Thai genus. An extremely long leg 4 was noted by van der Hammen (1968) as unique for Paracarus among opilioacarids. Similar limb proportions are present in the present fossil too, although whereas leg 4 is actually longer than leg 1 in the living $P$. hexophthalmus, leg 1 is a little longer than leg 4 in the fossil. By comparison, in the two Siamacarus species, leg 1 is about twice the length of leg 4 (Leclerc 1989, tables 1 \& 2). The reluctance of some previous authors to provide complete pictures of whole animals with legs attached, and van der Hammen's idiosyncratic approach to illustration in particular, does not make comparative studies of gross morphology particularly easy, but this fossil does fit Paracarus better than any other genus. The present authors assign it to this taxon, rediagnosing Paracarus simply on the elongate leg 4 .

\section{Paracarus pristinus sp. $\mathrm{n}$.}

Derivation of name. From the Latin 'pristinus', meaning old or former.

Holotype. Laboratory of Arachnology in Straubenhardt: F1011/BB/AR/CJW.

Horizon and locality. Tertiary Baltic amber forest; Baltic amber from Central Europe. The exact collection locality is unknown, but may have been in the vicinity of Kaliningrad, Baltic coast of Russia.

Diagnosis. Fossil Paracarus with posterior half of idiosoma beginning with two to three short anterior tergites; successive tergites longer. Chelicerae relatively long and legs more slender than those of $P$. hexophthalmus, basitarsus of legs 2-4 distinctly longer than either the tibia or telotarsus.

Description. Body essentially oval in outline. Dorsal body surface and legs with fine pustulate ornament. Total body length $1.79 \mathrm{~mm}$, maximum width $0.82 \mathrm{~mm}$. Idiosoma divided into sub-triangular head shield, length $0.66 \mathrm{~mm}$, and segmented posterior region, length $1.13 \mathrm{~mm}$. Head shield bears two groups of three eyes separated from a median region bearing papilliform setae by a pair of oculorostral grooves. Little tagmosis between two body regions. Anterior segments very short, c. $0.03 \mathrm{~mm}$, marginally forming laterodorsal sigilla. Succeeding segments longer, c. $0 \cdot 18 \mathrm{~mm}$. Anal tubercle at posterior end indistinct. Ventrally, pedipalps short, pediform and distally setose. Chelicerae formed from three articles, middle one $0.23 \mathrm{~mm}$ long with pseudoarticulation about half way along its length; distally forming fixed finger of claw. Rutellum immediately below chelicerae bearing at least five marginal dentate projections. Leg coxae barrelshaped. Verruca-like element adjacent to coxa 4. Postcoxal region with series of segments, length c. $0 \cdot 06-0 \cdot 08 \mathrm{~mm}$, becoming wider posteriorly and forming ventral sigilla at their margins. Posterior end of ventral surface without segmentation.

Legs generally slender, ornamented with combination of rows of ordinary setae and erect papilliform setae; particularly long on leg 4. Leg 1 slightly disarticulated from body, article lengths: trochanter $0.54 \mathrm{~mm}$, femur $1.22 \mathrm{~mm}$, patella $0.85 \mathrm{~mm}$, tibia $1.14 \mathrm{~mm}$, basitarsus $0.41 \mathrm{~mm}$, telotarsus $0.43 \mathrm{~mm}$. Leg 2 article lengths: trochanter $0.20 \mathrm{~mm}$, femur $0.63 \mathrm{~mm}$, patella $0.39 \mathrm{~mm}$, tibia $0.45 \mathrm{~mm}$, basitarsus $0.56 \mathrm{~mm}$, telotarsus $0.34 \mathrm{~mm}$. Leg 3 article lengths: trochanter $0.20 \mathrm{~mm}$, femur $0.39 \mathrm{~mm}$, patella $0.39 \mathrm{~mm}$, tibia $0.38 \mathrm{~mm}$, basitarsus $0.57 \mathrm{~mm}$, tarsus at least $0.20 \mathrm{~mm}$. Leg 4 article lengths: first trochanter $0.35 \mathrm{~mm}$, second trochanter $0.28 \mathrm{~mm}$, femur c. $0.70 \mathrm{~mm}$, patella $0.67 \mathrm{~mm}$, tibia $0.70 \mathrm{~mm}$, basitarsus $0.85 \mathrm{~mm}$, tarsus $0.40 \mathrm{~mm}$. Leg 4 ends in paired claws plus pulvillus. Leg 1 $(4.59 \mathrm{~mm})$ longer than leg $4(3.95 \mathrm{~mm})$, both over twice the length of the body.
Order Solifugae Sundevall, 1833

Family Daesiidae Kraepelin, 1899

Sub-family uncertain

Remarks. Twelve families of extant Solifugae are currently recognised (e.g. Punzo 1998; Harvey 2003). With its small size, fairly elongate opisthosoma and rather short, stout pedipalps, the present fossil resembles extant members of the family Daesiidae, such as the African to Middle Eastern genus Blossia Simon, 1880 or the Iberian genus Gluvia C. L. Koch, 1842. Some characters in the original diagnosis of the family (Roewer 1932-4) refer to the ventral surface and cannot be observed in the fossil. However combining features from recent keys in Punzo (1998), El-Hennawy (1999) and Harvey (2003), the present authors refer this fossil to Daesiidae because of its general body shape and the specific combination of: (1) very small size and (2) fused exterior lobes of the propeltidium. Precise details of male flagellum mobility, the female genital operculum and the presence/absence of claws on leg 1 remain equivocal in the fossil. The family Karschiidae has a similar exterior lobe morphology - described in keys as posteriorly fused - and also occurs in southern Europe, but the apparently simple-looking male flagellum in this fossil tends to rule out karschiids, which diagnostically have a complex fan-like to coiled flagellum structure.

Daesiidae currently includes six sub-families which have traditionally been distinguished from each other based (almost solely) on their tarsal segmentation and ventral tarsal spination (e.g. El-Hennawy 1999). In this scheme, the present fossil with two segments in tarsus 4 would match the sub-families Blossiinae and Triditarsinae, but the absence of unequivocal tarsal segment counts for the remaining legs (1-3) - these are obscured by emulsion in ventral view - makes it hard to resolve between these alternatives. The lack of clear ventral spination in the fossil is more like Triditarsinae, but authors such as Wharton (1981) have cautioned that the distinction between hairs and spines is sometimes a matter of personal interpretation, and the present authors can confirm the difficulty in making such judgements even with Recent daesiid material. Harvey (2003) cautioned that solifuge higher systematics remain chaotic and many of the currently recognised groups may not be monophyletic. Intuitively, this fossil looks like a small blossiine, but as is even the case for some Recent species, it cannot easily be placed into an existing daesiid subfamily or genus, as currently defined. Pending a revision of Daesiidae, the present authors prefer to leave its sub-familial position open.

\section{Genus Palaeoblossia gen. n.}

Derivation of name. Named for a fossil inclusion with considerable morphological similarities to the extant genus Blossia.

Type and only species. Palaeoblossia groehni gen. et sp. n.

Diagnosis. Very small fossil daesiid solifuge in which the leg 4 tarsus consists of two sub-equal segments lacking ventral leg spines or bristles.

Remarks. Since the tarsus 4 morphology of the present fossil cannot be matched exactly to any of the Recent daesiid genera, the authors feel obliged to raise a new taxon of uncertain sub-familial status based on the combination of two segments in tarsus 4 and the lack of unequivocal spination. Further material showing details of the remaining limbs or tarsus 4 (and any spines) in a different orientation may alter these interpretations. Generally, the fossil closely resembles extant Blossia solifuges (JAD, pers. obs.), and conceivably, belongs in this genus. However, it is somewhat smaller than the extant Blossia species available to the authors. In terms of overall size, 
this fossil is most similar to the European Gluvia (subfamily Gluviinae), but can be excluded from this taxon, which is characterised by three tarsal segments (e.g. El-Hennawy 1999).

Palaeoblossia groehni gen. et sp. n.

2002 Solifugae, Janzen, pp. 24, 76, figs. 4, 87-8.

Derivation of name. After Carsten Gröhn (Hamburg), who kindly made the holotype available for study.

Holotype. GPIUH 4312. No additional material.

Horizon and locality. Tertiary Baltic amber forest; Baltic amber from Central Europe. The exact collection locality is unknown, but may have been in the vicinity of Kaliningrad, Baltic coast of Russia.

Diagnosis. As for the genus.

Description. Total length (including chelicerae) $5.03 \mathrm{~mm}$. Propeltidium length $0.91 \mathrm{~mm}$, maximum width (across exterior lobes) $1.11 \mathrm{~mm}$. Anterior margin procurved, not straight. Propeltidium lightly setose, anteriorly with ocular tubercle, width $0.28 \mathrm{~mm}$, bearing single pair of median eyes. Median sulcus divides propeltidium behind ocular tubercle. Anterolateral exterior lobes incompletely separated from propeltidium by short sulci. Narrow arcus anterior/plagula mediana, length c. $0.05 \mathrm{~mm}$, follows propeltidium. Arcus posterior, meso- and metapeltidium indistinct, but further setae arise in this region. Opisthosoma elongate, widest about two-thirds of the way along its length, length c. $2.40 \mathrm{~mm}$, maximum width c. $1.00 \mathrm{~mm}$; segmented. Individual tergites range in length from 0.25 to $0.30 \mathrm{~mm}$. Tergites smooth, but with distinct pattern of rows of medium length setae. Posteriormost tergites more densely setose with very long tactile hairs.

Chelicerae massive, chelate, dentate, tapering distally and setose. Medially bearing stridulatory apparatus. Length c. $1.00 \mathrm{~mm}$, inserting at an angle to the body, maximum width $0.44 \mathrm{~mm}$. Mesal edge of chelicera in dentate region with brush of plumose setae. Each chelicera bears a simple, awl-like, forward-pointing flagellum, length $0 \cdot 13 \mathrm{~mm}$. Pedipalps robust and setose; femur-tibia bearing one or more very long tactile hairs. Pedipalp article lengths: femur $1.04 \mathrm{~mm}$, patella $0.72 \mathrm{~mm}$, tibia $0.74 \mathrm{~mm}$, tarsus $0.24 \mathrm{~mm}$. Walking leg 1 slender and gracile; highly setose. Leg 1 article lengths: basifemur $0.13 \mathrm{~mm}$, telofemur $0.20 \mathrm{~mm}$, patella $0.69 \mathrm{~mm}$, tibia $0.72 \mathrm{~mm}$, basitarsus $0 \cdot 39 \mathrm{~mm}$. Distal end of leg 1 indistinctly preserved. Legs 2-3 more robust and highly setose; only proximal regions visible. Leg 3 patella with at least one very long tactile hair. Leg 2 podomere lengths: basifemur $0.26 \mathrm{~mm}$, telofemur $0.11 \mathrm{~mm}$, patella $0.53 \mathrm{~mm}$. Leg 3 article lengths: basifemur $0.30 \mathrm{~mm}$, telofemur $0.28 \mathrm{~mm}$, patella $0.81 \mathrm{~mm}$, tibia $0.72 \mathrm{~mm}$.

Leg 4 distinctly larger and more robust than preceding legs. Patella, tibia and basitarsus with very long tactile hairs. Patellae stout, more distal article becoming increasingly slender. Leg 4 article lengths: basifemur $0.31 \mathrm{~mm}$, telofemur $0.1 \mathrm{~mm}$, patella $1.37 \mathrm{~mm}$, tibia $1.37 \mathrm{~mm}$, basitarsus $1.00 \mathrm{~mm}$, telotarsus $0.59 \mathrm{~mm}$. Telotarsus 4 subdivided into two subequal sections, distal segment slightly longer. Both highly setose, with very long tactile hair emerging dorsally on proximal segment. Ventrally setose, but lacking spines. Claws long, with tiny apical claws. Fleshy, rounded pulvillus emerges between claw bases.

\section{Discussion}

\subsection{Opilioacariformes}

The biology of Recent opilioacariform mites remains poorly known because of the lack of observations on these animals in life. Specimens in captivity have been observed eating crushed insects, pollen and fungal hyphae (Walter \& Proctor 1998), and pollen-eating was also observed by Klompen (2000). This omnivorous and/or scavenging diet, and the ability to ingest solid particles of food without preoral digestion (see also van der Hammen 1989), are similar to feeding patterns in harvestmen, and Walter \& Proctor (1998) further suggested that this combination of scavenging and opportunistic predation might be a ground pattern behaviour of mites inherited from ancestral chelicerates. Opilioacariform mites have typically been collected by day under stones (van der Hammen 1977; Lehtinen 1980; Walter \& Proctor 1998; Klompen 2000), and thus, it has been tentatively suggested that they are night-active creatures. The fine structure of their eyes (Kaiser \& Alberti 1991) is unique among mites and includes a tapetum, which would be consistent with increased light sensitivity in darkness. Other observations suggest that the animals are quite active and climb readily in captivity (Walter \& Proctor 1998). Mating behaviour is unknown, but sperm structure was described by Alberti (1980) and egg laying under laboratory conditions was reported by Klompen (2000).

Harvey (1996) illustrated the present day distribution of opilioacariform mites, to which undescribed Australian examples from northern Queensland (Walter \& Proctor 1998) must now be added. The majority of records are African and South or Central American, leading van der Hammen (1970) to speculate that the entire group had a Gondwanan origin. The Baltic amber fossil does not really support this hypothesis. This suggestion was also criticised by Leclerc (1989) based on his south-east Asian material. The putative sister-taxon of the present fossil, the extant $P$. hexopthalmus, has been recorded from the type locality of 'Semiretshje, Alexander Bergkette', which is the Kigizskij Khrebet [= Kirgizki Hrebet], a mountain range on the border between Kazakhstan and Kyrgyzstan, and from a second locality in Kazakhstan (van der Hammen 1968). The present authors are not aware of any other Baltic amber arachnid group which shows such a pattern in which the closest living relatives are limited to central Asia.

In fact, the closest geographical records to this amber specimen are examples of Opilioacarus italicus (With, 1904) from the Mediterranean (With 1904; Brignoli 1967; Beron 1990; Thaler \& Knoflach 2002), specifically Italy and Greece, including some Aegean islands. Thus, together with the species from the southern USA and central Asia, the northern limit of their Recent distribution seems to be about $41-43^{\circ} \mathrm{N}$. The present authors lack an exact type locality for their fossil, but this Baltic amber opilioacariform mite corresponds to a region of about $55^{\circ} \mathrm{N}$, and even allowing for a slight northward shift of Europe during the Tertiary, it is clearly the most northerly record of the group. Indeed fossil and Recent ranges of arachnid taxa are often disjunct, and there is a considerable amount of palaeontological data in the form of northern hemisphere fossil representatives of Recent austral taxa, which tends to be the rule rather than the exception. A good example is the spider family Archaeidae, which has been recorded from Tertiary Baltic amber and from the Jurassic of Kazakhstan (Eskov 1987), but which is today restricted almost entirely to South Africa, Madagascar and Australia; see also Eskov \& Golovatch (1986) for a more general discussion.

The present fossil opilioacarid mite shows that the group was once more widely distributed within Eurasia. Furthermore, it has been suggested that opilioacarids are typical of arid habitats. This rather general observation only seems to apply to extant Old World taxa (Vázquez \& Klompen 2002), but given the presence of a solifuge (see section 5.2), could be applicable to the Old World Baltic amber species too. 


\subsection{Solifugae}

Relatively little is known about the biology of extant daesiid solifuges, especially the few European species. Bellmann (1997) noted that the Iberian genus Gluvia includes aggressive, fastmoving animals which occur in very dry steppe to desert-like environments. They live on the ground and typically spend the day under stones or in a burrow, emerging at night to hunt for small arthropod prey, which they detect with their long, tactile hairs. A similar mode of life seems appropriate for this fossil species. Solifuge biology in general has been summarised by Punzo (1998), and given the fully modern appearance of this fossil, the present authors have little reason to doubt that it lived in a similar way to extant taxa. This 5-mm-long fossil is very small, and the flagellum suggests that it was mature or, at least, very close to maturity. According to El-Hennawy (1999), recent daesiids are the smallest solifuges and have body lengths of c. 6-23 mm; thus, this fossil is very much at the lower end of this range. If further material should provide unequivocal evidence of maturity, the present authors may, in fact, have the smallest solifuge species yet known.

Recent Daesiidae are among the most diverse solifuges, with 189 species in 28 genera listed by Harvey (2003). These are distributed across Africa, southern Europe, the near East and South America. Coherent studies of phylogeny and biogeography for Solifugae are lacking, thus the wider significance of the present fossil is currently hard to assess. Like the opilioacariform mite, this early Tertiary fossil is the most northerly record of a solifuge and indicates that the group was originally much more widespread in Europe. According to Punzo (1998, figs 7-11), the most northerly distributed extant taxa are found in central Asia, but not as far north as the Baltic amber forest region. Most solifuges are also strongly associated with arid environments, but the bearing of this material on palaeo-environmental reconstructions must be tested against other plant and animal inclusions.

\section{Acknowledgements}

We thank Carsten Gröhn (Hamburg) for allowing us to study the solifuge. Bill Shear kindly provided extant opilioacarid material for comparison. We thank Hans Klompen, Mark Judson and Wilfried Wichard for useful comments and additional literature, Oliver Coleman (Berlin) for help with photography, and Natasha Unwin for help translating Zachvatkin's paper. We are also grateful to Mark Harvey and an anonymous reviewer for their remarks on an earlier version of the manuscript.

\section{References}

Alberti, G. 1980. Zur Feinstruktur der Spermien und Spermiocytogenese der Milben (Acari). I. Anactinotrichida. Zoologische Jahrbücher, Anatomie 104, 77-138.

Bellmann, H. 1997. Kosmos Atlas Spinnentiere Europas. 2. Auflage. Stuttgart: Frankh-Kosmos Verlags-GmbH.

Bernini, F. 1986. Current ideas on the phylogeny and the adaptive radiations of Acarida. Bollettino di Zoologia 53, 279-313.

Bernini, F., Carnevale, G., Bagnoli, G. \& Stouge, S. 2002. An Early Ordovician oribatid mite (Acari: Oribatida) from the island of Öland, Sweden. In Bernini, F., Nannelli, R., Nuzzaci, G. \& de Lillo, E. (eds). Acarid Phylogeny and Evolution. Adaptations in Mites and Ticks, 45-7. Dordrecht: Kluwer Academic Publishers.

Beron, P. 1990. On the occurence of Opilioacarus segmentatus (With, 1903) (Arachnida, Opilioacarida) on the islands of Kassos, Karpathos and Rhodes (Greece). Acta Zoologica Bulgarica 39, 64-6.

Brignoli, P. M. 1967. Su Opilioacarus italicus (With) (Acarina, Notostigmata). Fragmenta Entomologica 5, 111-21.

Chamberlin, R. V. \& Mulaik, S. 1942. On a new family in the Notostigmata. Proceedings of the Biological Society of Washington 55, 125-32.
Coineau, Y. \& Hammen, L. van der. 1979. The postembryonic development of Opilioacarida, with notes on new taxa and on a general model for the evolution. In Pfiffl, E. (ed.) Proceedings of the $4^{\text {th }}$ International Congress of Acarology, Saalfelden 1974, 437-41, Budapest: Akadémiai Kiadó.

Coineau, Y. \& Legendre, R. 1975. Sur un mode de régénération appendiculaire inédit chez les Arthropodes: la régénération des pattes marcheuses chez les Opilioacariens (Acari: Notostigmata). Compte Rendu des séances de l'Académie Sciences, Paris 280, 41-3.

Coineau, Y. \& Magowski, W. Ł. 1994. Caeculidae in amber. Acarologia 35, 243-6.

Delle Cave, L. \& Simonetta, A. M. 1971. A tentative revision of the Daesiidae (Arachnida, Solifugae) from Ethiopia and Somalia. Monitore Zoologico Italiano N. S. 2, 37-77.

Dunlop, J. A. \& Martill, D. M. in press. Four additional specimens of the fossil camel spider Cratosolpuga wunderlichi Selden 1996 (Arachinida: Solifugae) from the Lower Cretaceous Crato Formation of Brazil. Revista Ibérica de Aracnología.

Dunlop, J. A. \& Rößler, R. 2003. An enigmatic, solifuge-like fossil arachnid from the Lower Carboniferous of Kamienna Góra (Intra-Sudetic Basin), Poland. Paläontologische Zeitschrift 77, 389-400.

El-Hennawy, H. K. 1999. Sun spiders of the Arab countries (Arachnida: Solpugida). Serket 6, 73-104.

Eskov, K. Y. 1987. A new archaeid spider (Chelicerata: Araneae) from the Jurassic of Kazakhstan, with notes on the so-called 'Gondwanan' ranges of recent taxa. Neues Jahrbuch für Geologie und Paläontologie, Abhandlungen 175, 81-106.

Eskov, K. Y. \& Golovatch, S. I. 1986. On the origin of trans-Pacific disjunctions. Zoologische Jahrbücher, Systematik 113, 265-85.

Evans, G. O. 1992. Principles of acarology. Wallingford: C.A.B. International.

Grandjean, F. 1936. Un Acarien synthétique: Opilioacarus segmentatus With. Bulletin de la Société d'Histoire Naturelle de l'Afrique du Nord 27, 413-44.

Hammen, L. van der. 1968. Studies on Opilioacarida (Arachnida) II. Redescription of Paracarus hexophthalmus (Redikorzev). Zoologische Mededelingen 43, 57-76.

Hammen, L. van der. 1970. La phylogenèse des opilioacarides, et leurs affinités avec les autres Acariens. Acarologia 12, 465-73.

Hammen, L. van der. 1976. Glossaire de la terminologie acarologique, Vol. 2. Opilioacarida. The Hague: Dr W. Junk bv.

Hammen, L. van der. 1977. Studies on Opilioacarida (Arachnidea) IV. The genera Panchaetes Naudo and Salfacarus gen. nov. Zoologische Mededelingen 54, 43-78.

Hammen, L. van der. 1989. An introduction to comparative arachnology. The Hague: SPB Academic Publishing.

Harvey, M. 1996. Small arachnids and their value in Gondwanan biogeographic studies. In Hopper, S. D. et al. (eds) Gondwanan heritage; past, present and future of the Western Australian biota, 155-62. Chipping Norton: Surrey Beatty \& Sons.

Harvey, M. 2002. The neglected cousins: What do we know about the smaller arachnid orders? Journal of Arachnology 30, 357-72.

Harvey, M. 2003. Catalogue of the smaller arachnid orders of the world: Amblypygi, Uropygi, Schizomida, Palpigradi, Ricinulei and Solifugae. Collingwood: CSIRO Publishing.

Hirst, S. 1923. On some arachnid remains from the Old Red Sandstone (Rhynie Chert bed, Aberdeenshire). Annals and Magazine of Natural History, Series 9 12, 455-74

Janzen, J.-W. 2002. Arthropods in Baltic amber. Halle (Saale): AmpyxVerlag Dr Andreas Stark.

Johnston, D. E. 1968. An atlas of Acari. I. The families of Parasitiformes and Opilioacariformes. Publication No. 172. Columbus, Ohio: Acarology Laboratory, The Ohio State University.

Kaiser, T. \& Alberti, G. 1991. The fine structure of the lateral eyes of Neocarus texanus Chamberlin \& Mulaik, 1942 (Opilioacarida, Acari, Arachnida, Chelicerata). Protoplasma 163, 19-33.

Keilbach, R. 1982. Bibliographie und Liste der Arten tierischer Einschlüsse in fossilen Harzen sowie ihre Aufbewahrungsorte. Deutsche Entomologische Zeitschrift N.F. 29, 129-286.

Klompen, J. S. H. 2000. Prelarva and larva of Opilioacarus (Neocarus) texanus (Chamberlin and Mulaik) (Acari: Opilioacarida) with notes on the patterns of setae and lyrifissures. Journal of Natural History 34, 1977-92.

Klompen, J. S. H. \& Grimaldi, D. 2001. First Mesozoic record of a parasitiform mite, a larval argasid tick in Cretaceous amber (Acari: Ixodida: Argasidae). Annals of the Entomological Society of America 94, 10-15. 
Koch, C. L. 1842. Systematische Uebersicht über die Familie der Galeoden. Archiv für Naturgeschichte 8, 350-6.

Kraepelin, K. 1899. Zur Systematik der Solifugen. Mitteilungen aus dem Naturhistorischen Museum in Hamburg 16, 195-258.

Leclerc, P. 1989. Considerations paleobiogeographiques a propos la decouverte en Thailande d'Opilioacariens nouveuax (Acari Notostigmata). Compte Rendu des Seances, Société de Biogeographie, Paris 65, 162-74.

Lehtinen, P. T. 1980. A new species of Opilioacarida (Arachnida) from Venezuala. Acta Biologica Venzuelica 10, 205-14.

Lourdes, M. 1999. Los Ácaros: Origen, Evolución y Filogenia. In Melic, A., de Haro, J. J., Mendez, M. \& Ribera, I. (eds) Evolución y Filogenia de Arthropoda. Boletin de la Sociedad Entomológica Aragonesa 26, 281-92.

Norton, R. A., Bonamo, P. M., Grierson, J. D. \& Shear, W. A. 1988. Oribatid mite fossils from a terrestrial Devonian deposit near Gilboa, New York. Journal of Paleontology 62, 259-69.

Poinar, G. O. \& Santiago-Blay, J. A. 1989. A fossil solpugid, Happlodontus proterus, new genus, new species (Arachnida: Solifugae) from Dominican amber. Journal of the New York Entomological Society 97, 125-32.

Punzo, F. 1998. Biology of camel-spiders (Arachnida, Solifugae). Boston, Massachusetts: Kluwer Academic Publishers.

Redikorzev, V. 1937. Eine neue Opilioacarus-Art. Zoologischer Anzeiger 118, 10-12.

Roewer, C.F. 1932-4. Solifugae, Palpigradi. In Bronns, H.G. (ed.) Klassen und Ordnungen des Tierreichs. 5: Arthropoda. IV: Arachnoidea, Vol. 5 (IV) (4) (1-5), 1-723. Leipzig: Akademische Verlagsgesellschaft M.B.H.

Sayre, R. M., Smiley, R. L. \& Walter, D. E. 1992. Report of a teneriffiid mite (Acari) in Baltic amber and notes on recent discoveries. International Journal of Acarology 18, 303-5.

Selden, P. A. 1993. Arthropoda (Aglaspidida, Pycnogonida and Chelicerata). In Benton, M. J. (ed.). The Fossil Record 2, 297-320. London: Chapman \& Hall.

Selden, P. A. \& Shear, W. A. 1996. The first Mesozoic solifugae (Arachnida), from the Cretaceous of Brazil and a redescription of the Palaeozoic Solifugae. Palaeontology 39, 583-604.
Shultz, J. W. 1989. Morphology of locomotor appendages in Arachnida: evolutionary trends and phylogenetic implications. Zoological Journal of the Linnean Society 97, 1-56.

Simon, E. 1880. Descriptions de deux nouveaux genres de l'ordre des Solifugae. Annales de la Société Entomologique de France (5) 10, 399-402.

Sundevall, J. C. 1833. Conspectus Arachnidum. Londini Gothorum.

Thaler, K. \& Knoflach, B. 2002. Neue Opilioacarus-Funde (Acari, Notostigmata) in Peloponnes und Ägäis (Griechenland). Entomologische Nachrichten und Berichten 46, 271-7.

Vázquez, M. M. \& Klompen, H. 2002. The family Opilioacaridae (Acari: Parasitiformes) in north and central America, with descriptions of four new species. Acarologia 42, 299-322.

Vitzthum, H. G. 1931. Acari=Milben. In Kükenthal, W. (ed.) Handbuch der Zoologie, Vol. III. 2. (3), 1-160. Berlin: Walter de Gruyter \& Co.

Walter, D. E. \& Proctor, H. C. 1998. Feeding behaviour and phylogeny: observations on early derivative Acari. Experimental and Applied Acarology 22, 39-50.

Walter, D. E. \& Proctor, H. C. 1999. Mites: ecology, evolution and behaviour. Wallingford: University of New South Wales Press and CAB International.

Wharton, R. A. 1981. Namibian Solifugae (Arachnida). Cimbebasia 5, $1-87$.

Witaliński, W. 2000. Aclerogamasus stenocornis sp. n., a fossil mite from the Baltic amber (Acari: Gamisida: Parasitidae). Genus 11, 619-26.

With, C. J. 1902. A new acaride Opilioacarus segmentatus. Compte Rendu des Congre des Naturaliste et Medicins du Nord 20, 4-5.

With, C. J. 1904. The Notostigmata. A new suborder of Acari. Videnskabelige meddelelser fra den Naturhistoriske Forening $i$ Kjøbenhavn 1904, 137-92.

Zachvatkin, A. A. 1952. The division of the Acarina into orders and their position in the system of the chelicerata. Parazitologicheskii Sbornik Zoologicheskii Institut Akademii Nauk SSSR 14, 5-46. [In Russian.]

JASON A. DUNLOP, Institute für Systematische Zoologie, Museum für Naturkunde der Humboldt-Universität zu Berlin, Invalidenstraße 43, D-10115 Berlin, Germany. e-mail: jason.dunlop@museum.hu-berlin.de

JÖRG WUNDERLICH, Hindenburgstraße 94, D-75334 Straubenhardt, Germany.

e-mail: joergwunderlich@t-online.de

GEORGE O. POINAR Jr., Department of Zoology, Oregon State University, Corvallis, OR 97331-2914, USA.

e-mail: poinarg@casco.net

MS received 10 October 2003. Accepted for publication 15 March 2004. 